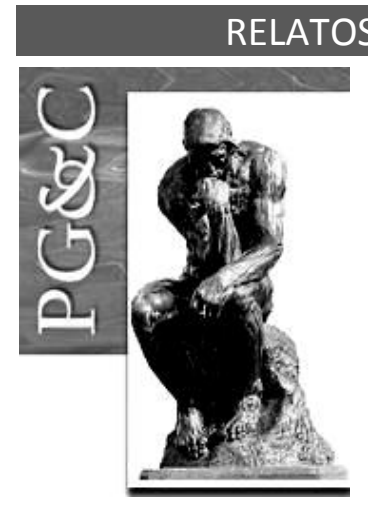

\title{
O USO DE ONTOLOGIAS NO REGISTRO DE LIÇÕES APRENDIDAS EM PROJETOS GERENCIADOS COM SCRUM
}

\author{
Mauricio Augusto Cabral Ramos Junior \\ Doutorando em Ciência da Informação pela Universidade Federal \\ Fluminense, Brasil. \\ E-mail: macrjunior@hotmail.com \\ Regina de Barros Cianconi \\ Doutora em Ciência da Informação pela Universidade Federal do Rio de \\ Janeiro, Brasil. Professora da Universidade Federal Fluminense, Brasil. \\ E-mail: rcianconi@globo.com
}

\begin{abstract}
Resumo
O objetivo deste artigo é discorrer como, por meio do uso de ontologias como suporte à aplicação de métodos de apuração de lições aprendidas, pode ser estabelecida uma relação entre Gestão do Conhecimento e Gestão de Projetos gerenciados segundo os preceitos do Scrum. Neste intuito, é realizada uma pesquisa bibliográfica, qualitativa e exploratória, buscando textos em bases de dados, livros e periódicos eu abordam as temáticas estudadas. Foram encontrados textos na Ciência da Informação, Ciência da Computação e Administração de Empresas que tratam de aspectos do relacionamento entre os temas pesquisados. A análise da literatura mostra que a Gestão do Conhecimento e a Gestão de Projetos são atividades complementares, que possuem pontos de encontro orientados ao fortalecimento do aprendizado e, portanto, devem ser conduzidas de maneira integrada, através de indivíduos, medidas organizacionais e tecnologias da informação e comunicação. Como parte da análise dos resultados é construído um mapa conceitual para ilustrar como os temas estudados se relacionam. $O$ estudo conclui que o uso de ontologias favorece a aplicação de métodos de registro de lições aprendidas em projetos gerenciados através do Scrum, para validar, organizar e representar o considerável conhecimento tácito que é comumente empregado nestes projetos.
\end{abstract}

Palavras-chave: Gestão do Conhecimento. Gestão de Projetos. Scrum. Lições Aprendidas. Ontologia.

\section{THE ONTOLOGIES USED TO REGISTER LESSONS LEARNED ON A SCRUM PROJECT}

\begin{abstract}
The objective of this article is to discuss how, through the use of ontologies as support to the application of methods of calculating lessons learned, a relationship can be established between Knowledge Management and Project Management managed according to Scrum precepts. For this purpose, a qualitative and exploratory bibliographical research is carried out, searching texts in databases, books and periodicals of the studied areas. We found texts in Information Science, Computer Science and Business Administration that deal with aspects of the relationship between the researched topics. The analysis of the literature shows that, although apparently watertight, Knowledge Management and Project Management have meeting points oriented to the strengthening of learning and, therefore, should be conducted in an integrated way, through individuals, measures organizational and information and communication technologies. As part of the analysis of results, a conceptual map is constructed to illustrate how the themes studied are related. Thus, the study concludes that the use of ontologies favors the application of lessons learned methods in projects managed through Scrum, to validate, organize and represent the considerable tacit knowledge that is commonly used in these projects.
\end{abstract}

Keywords: Knowledge management. Project management. Scrum. Lessons Learned. Ontology.

Perspectivas em Gestão \& Conhecimento, João Pessoa, v. 9, n. 1, p. 82-100, jan./abr. 2019. DOI: http://dx.doi.org/10.21714/2236-417X2019v9n1p82

http://periodicos.ufpb.br/ojs2/index.php/pgc. ISSN: 2236-417X. Publicação sob Licença (cc) EY-NC-ND 


\section{INTRODUÇÃO}

Uma importante atividade na organização e representação do conhecimento no contexto organizacional é o registro de lições aprendidas (lessons learned), que podem ser definidas como ensinamentos significativos obtidos a partir da vivência de experiências de alguma forma relacionadas a atividades organizacionais. Em geral, as lições aprendidas são apuradas a partir da aplicação de métodos próprios, que envolvem reuniões entre os participantes de atividades que as originaram (como a Gestão de Projetos, por exemplo), e registradas para disponibilização, após terem sua relevância consensualmente ratificada, constituindo um subsídio importante para a elaboração de melhores práticas nas organizações.

O conhecimento que uma organização possui é formado, e frequentemente aprimorado, pelo conhecimento oriundo de seus colaboradores, que vivenciam experiências enquanto executam as atividades organizacionais que Ihes são confiadas. Uma destas atividades, na verdade um grupo delas, são os projetos, iniciativas geralmente estratégicas conduzidas por uma equipe destinada a executar racionalmente um conjunto de atividades necessárias à consecução de um ou mais objetivos organizacionais. Por suas características, os projetos oferecem oportunidades de aprendizado individual e, consequentemente, organizacional, propiciando o aprimoramento do conhecimento tácito, que pode ser, por sua vez, representado pelo conhecimento explicitado no registro de lições aprendidas.

Uma das formas de compartilhamento do conhecimento é por meio do registro das lições aprendidas, uma prática utilizada na Gestão do Conhecimento, conforme Sechhi (1999 apud Sharif et al. 2005). Segundo este autor, lições aprendidas "são conhecimentos de trabalho validados derivados de sucesso ou fracasso, que quando utilizados podem impactar significativamente o processo de uma organização.". Assim, o registro de lições aprendidas deve ser realizado com critério, buscando o que se perceba como capaz de oferecer uma vantagem para a organização. Neste sentido, a utilização de uma ontologia - um modelo de representação do conhecimento adquirido sobre um determinado assunto - pode ser útil, ao oferecer uma representação legitimada do conhecimento organizacional.

Os projetos, entretanto, costumam sofrer restrições de escopo, prazo e custo, o que estimula a busca de formas eficientes de gerenciá-los. Assim, os últimos anos presenciaram o advento de metodologias e frameworks de gerenciamento dito ágil de projetos, como o framework Scrum, um processo para o desenvolvimento ágil de um produto qualquer. 0 conceito de desenvolvimento ágil diz respeito a um conjunto de métodos e práticas baseadas nos princípios expressos no "Manifesto para o Desenvolvimento Ágil de Software", apresentado em 2001, que ficou conhecido como Manifesto Ágil (Agile Manifest) (TELES, 2008) e prevê a utilização de equipes multidisciplinares, colaborativas e auto-organizadas.

Possuindo uma característica comum a metodologias e frameworks ágeis, o Scrum busca reduzir o prazo de execução dos projetos, priorizando as entregas planejadas e o compartilhamento do conhecimento. As respectivas equipes de projeto, por consequência, não raro são imediatamente alocadas em um novo projeto (ou simplesmente desmobilizadas, muitas vezes não retornando à organização, como no caso de consultores externos) tão logo o anterior termine, sem haver uma apuração formal de eventuais lições aprendidas. Assim, há o risco de não aproveitamento de oportunidades de aprimorar o conhecimento organizacional.

Por sua vez, a Gestão do Conhecimento é um recurso estratégico para a melhoria do desempenho organizacional, e a este respeito, Von Grogh, Ichijo e Nonaka (2001) enfatizam que seus gestores devem promover a criação e o controle do conhecimento, processo que denominam capacitação para o conhecimento. Neste sentido, Nonaka e Konno (1998) propuseram o conceito de $B a$, um espaço subjetivo, interativo e compartilhado, de natureza

Perspectivas em Gestão \& Conhecimento, João Pessoa, v. 9, n. 1, p. 82-100, jan./abr. 2019 
física, virtual ou mental (ou uma combinação destas) e que favorece a integração de informações para o aprimoramento do conhecimento a nível individual e/ou coletivo, a partir de uma experiência própria ou reflexões sobre uma experiência alheia. O Ba pode ser visto como "contexto capacitante", um ambiente que encoraja a criação, compartilhamento e uso de informações e conhecimento e que dá suporte à produção do conhecimento, sendo um dos principais recursos para a criação e reutilização do conhecimento pelas organizações. (CHOO; ALVARENGA NETO, 2010).

Diante do que foi exposto, acredita-se que há semelhanças significativas entre o $B a$ e o contexto dos projetos gerenciados segundo os preceitos do Scrum e, sendo assim, a apuração de eventuais lições aprendidas pode se tornar um fator crítico de sucesso ao contribuir com a organização e representação do conhecimento organizacional, favorecendo seu compartilhamento e a consequente produtividade das equipes de projeto. Decorre desta afirmação, portanto, a crença em que o uso de ontologias pode favorecer à aplicação de métodos de registro de lições aprendidas em projetos gerenciados segundo os preceitos do Scrum, o que motivou a elaboração deste artigo.

A partir das temáticas estudadas como parte do marco teórico da tese de doutorado de um de seus autores, o objetivo deste artigo é identificar, através do uso de ontologias como suporte à aplicação de métodos de apuração de lições aprendidas, uma relação entre Gestão do Conhecimento e Gestão de Projetos gerenciados segundo os preceitos do Scrum. Neste intuito, foi realizada uma pesquisa bibliográfica, de cunho qualitativo, exploratório, em literatura nacional e internacional, tendo as buscas sido efetuadas em diferentes fontes, como em bases de dados como Scopus, Portal de Periódicos CAPES e Google Acadêmico, além de em diversos textos e livros já possuídos pelos autores. Nas buscas, em bases de dados científicas, as palavras-chaves "ontologias", "gestão do conhecimento", "gestão de projetos", scrum, "lições aprendidas", foram cruzadas entre si. Como os referidos temas muitas vezes não se encontram reunidos no mesmo texto, e boa parte das bases de dados só permitem cruzar termos dois a dois, foram feitas buscas com duas variáveis, por exemplo: ontologias AND "gestão do conhecimento"; ontologias AND "lições aprendidas"; ontologias AND "gestão de projetos"; ontologias AND scrum, e assim sucessivamente. Desta forma, foram obtidos textos das áreas da Ciência da Informação, Ciência da Computação e Administração de Empresas, que foram então analisados para apurar como os temas se inter-relacionam. Como parte do resultado desta análise, tem-se um mapa conceitual para ilustrar os relacionamentos encontrados, apresentado na Figura 2.

O artigo está estruturado da seguinte forma. Além desta Introdução, é apresentada uma breve descrição do contexto da Gestão do Conhecimento, enfatizando suas relações com a Gestão de Projetos através de seus instrumentos, como o registro de lições aprendidas e as ontologias. Em seguida, descreve-se o Scrum a partir de seus objetivos, características e práticas, relacionando-o à Gestão de Projetos. O próximo tópico trata da apuração e registro de lições aprendidas a partir de alguns de seus métodos para, em seguida, sugerir algumas aplicações de ontologias neste sentido e apresentar a conclusão do artigo.

\section{RELAÇÕES ENTRE GESTÃO DO CONHECIMENTO, ONTOLOGIA E PROJETO}

Embora haja uma diversidade de definições para a expressão "Gestão do Conhecimento", elas tem em comum alguns elementos, os quais permitem acreditar se tratar de uma gestão estratégica (WALTZ, 2003) baseada em processos de criação, organização, formalização, compartilhamento, aplicação e refinamento (NISSEN, 2006) do conhecimento, que, a partir da integração entre capital intelectual (tácito e explícito), cultura e valores individuais e organizacionais, favoreça a sustentabilidade de uma organização. A Gestão do Conhecimento depende dos mecanismos de criação e conversão de conhecimento da

Perspectivas em Gestão \& Conhecimento, João Pessoa, v. 9, n. 1, p. 82-100, jan./abr. 2019 
organização, da cultura organizacional, de recursos de busca e recuperação da informação, da capacidade de aprendizado organizacional, dos recursos para a preservação da memória organizacional. Envolve, portanto, os conhecimentos tácito e explícito.

Um fator crítico de sucesso na Gestão do Conhecimento é a forma como as organizações lidam com o compartilhamento de seus conhecimentos. Segundo Wons et al. (2018), há três tipos de barreiras ao efetivo compartilhamento do conhecimento organizacional:

a) individual: falta habilidade de comunicação; diferença cultural; receio de superação pelos colegas; ênfase no status/posição; perda de poder; receio de constrangimento; resistência interna; falta de tempo; motivação; identificação dos benefícios; mentalidade individualista; falta de profundidade nos relacionamentos; confiança; percepção de lacunas no conhecimento; e falta de reciprocidade.

b) organizacional: falta de infraestrutura e recursos; acessibilidade aos espaços formais e informais; idioma; prevenção de conflitos; ausência de cultura organizacional saudável; ausência de incentivos ou recompensas; linguagem; burocracia; limites/distância física; hierárquica; e conflitos de comunicação.

c) tecnológica: dificuldade no manuseio de ferramentas e sistemas; dificuldades em integrar e modificar os sistemas baseados em tecnologia; dificuldade ao acesso às ferramentas; falta de consciência da existência da partilha de conhecimento nas plataformas; ausência de treinamento e estímulos para a utilização das ferramentas; insuficiência de competência em tecnologia de informação; e instalações inadequadas.

As barreiras individuais ao compartilhamento do conhecimento foram objeto de estudo de Jugdev e Wishart (2014), que reuniram as atitudes e os comportamentos que as representam sob o conceito de Habituação (Habituation), que encontra suas raízes nas características psicossociais individuais. Segundo estes autores, o indivíduo em geral se sente pressionado a, e ao mesmo tempo resistente em, compartilhar conhecimento em suas atividades organizacionais (por exemplo, durante a execução de projetos nos quais participe), carecendo de um ambiente baseado no cuidado mútuo (Mutual Caring) para adquirir a confiança necessária para romper este círculo vicioso. Neste sentido, e segundo Santiago Júnior (2014), o aprendizado originado em discussões e compartilhamento de conhecimentos tácitos nem sempre é possível de se explicitar por causa, entre outros motivos, da relutância natural em fazê-lo, sobretudo se isto envolver experiências negativas.

A despeito de algumas características distintas como, por exemplo, o fato de que a Gestão do Conhecimento deva ser vista como uma atividade abrangente e permanente numa organização e a Gestão de Projetos tenha um escopo mais específico, com seu fim previsto a cada projeto realizado, a Gestão de Projetos apresenta vantagem quando relacionada à Gestão do Conhecimento. De fato, corroborando esta afirmação, para Jugdev e Wishart (2014) a Gestão de Projetos é uma disciplina baseada no aprimoramento do conhecimento pelo aprendizado obtido na experimentação, nos conhecimentos tácito e explícito e nas práticas formais de compartilhamento de conhecimento.

A ligação entre Gestão do Conhecimento e de projetos também foi reconhecida pelo $\mathrm{PMI}^{\circledR}$ (2018), uma referência mundial em Gestão de Projetos, que na última edição de sua base de conhecimento (o Guia $P M B O K^{\circledR}$ ) incluiu o processo "4.4 Gerenciar o Conhecimento do Projeto" para ressaltar a importância da Gestão do Conhecimento oriunda da execução de projetos; dentre as saídas deste processo estão as atualizações dos ativos de processos organizacionais que podem ser agrupados em duas categorias: "(1) processos e procedimentos, e (2) base de conhecimento corporativo", sendo que esta última compreende as lições aprendidas (bem como seu registro) e informações de caráter histórico.

Perspectivas em Gestão \& Conhecimento, João Pessoa, v. 9, n. 1, p. 82-100, jan./abr. 2019 
Para Tsui (2005), o conhecimento em uma organização é resultado da interação entre pessoas, processos, conteúdos e tecnologias da informação e comunicação, sendo que, para Nissen (2006), as pessoas executam o papel principal nos processos organizacionais. 0 conteúdo, por sua vez, é representado por unidades de conhecimento, que se constituem em pacotes atômicos do conhecimento explícito que pode ser rotulado, indexado, armazenado, recuperado e manipulado (ZACK, 1999). Como exemplo, Maier (2007) cita os documentos textuais eletrônicos que ilustram ideias, propostas, experiências, opinião especializada, descrição ou solução de um problema específico, melhor prática ou lição aprendida.

As tecnologias de informação e comunicação têm, em geral, a finalidade de organizar, formalizar e disseminar o conhecimento (RAUTENBERG, 2009), constituindo-se em três camadas tecnológicas de aplicação (WALTZ, 2003): Gestão do Conhecimento (prática cognitiva e organizacional, mediante redes de computadores e pessoas, para a criação e aplicação do conhecimento), computação (aplicação de fundamentos tecnológicos para incrementar comunicação e processamento) e informação (abstração e métodos computacionais, as bases dos softwares para organizar e combinar de dados de aplicações).

Com a finalidade de se atingir algum objetivo específico, a Gestão do Conhecimento se utiliza de instrumentos que intervém tecnológica e contextualmente na base de conhecimento organizacional, através da utilização conjunta de medidas organizacionais, indivíduos e tecnologias da informação e comunicação (MAIER, 2005). Ainda segundo Maier (2007), a utilização de tais instrumentos se traduz na busca de vantagem(s) competitiva(s). São exemplos de instrumentos de Gestão do Conhecimento, entre outros, as melhores práticas e as comunidades de prática, bem como as lições aprendidas (KEYES, 2006).

De acordo com Handzic e Durmic (2015), as organizações estão enfrentando desafios para melhor gerenciar os ativos de conhecimento no ambiente de projetos. Mostram que diversas organizações em todo o mundo trabalham com projetos integrados que consideram a Gestão do Conhecimento como um conceito complexo e multidimensional e, com apoio no conceito de $B a$, enfatizam a importância dos aspectos social e técnico, como fatores que facilitam os processos de conhecimento. Segundo Sousa, Costa e Aparício (2017), o Ba é um ambiente propício ao compartilhamento de conhecimento, fundamentado em quatro variáveis distintas e inter-relacionadas: Indivíduo (fatores relacionados ao cuidado mútuo entre os indivíduos), Organização (favorecimento da cultura organizacional), Social (influência social, normas subjetivas) e Virtual (infraestrutura tecnológica para a Gestão do Conhecimento).

Através da definição de classes, relações, instâncias e axiomas, Bloehdorn et al. (2006), acreditam na capacidade das ontologias de explicitar, sob a forma de um modelo, um determinado conhecimento acerca de uma visão relevante do mundo de maneira passível de processamento e interpretação por parte dos computadores.

De acordo com Saito, Umemoto e Ikeda (2007), a Ontologia é uma disciplina da Filosofia que estuda as categorias daquilo que existe ou deveria existir em um determinado domínio de conhecimento, sendo uma ontologia um resultado propriamente dito da aplicação dos ditames desta disciplina, e cujo nível de formalidade pode ser obtido progressivamente. Segundo Oliveira e Werneck (2003), um dos objetivos de uma ontologia é representar genericamente o conhecimento de um domínio para promover um entendimento compartilhado a seu respeito, como, por exemplo, o relacionado a processos de software.

Para Almeida (2006), uma ontologia pode ser abordada como objeto (definindo-a segundo a Filosofia, Inteligência Artificial e Ciência da Informação) ou processo (apresentando uma analogia entre os estágios de sua construção e o ciclo de vida de um software), constituindo-se em uma alternativa para representar modelos das organizações (como os relacionados à memória organizacional) a partir da retenção consensual de conhecimento obtido através de entrevistas com especialistas e usuários, análise de documentos por eles produzidos e do contexto onde o respectivo conhecimento foi gerado.

Perspectivas em Gestão \& Conhecimento, João Pessoa, v. 9, n. 1, p. 82-100, jan./abr. 2019 
Segundo Lin (2013), as ontologias são instrumentos de Gestão do Conhecimento que definem os termos usados para descrever e representar uma área de conhecimento específica, e podem ser usadas para construir estruturas de conhecimento, melhorando o acesso humano a informações e promovendo a reutilização do conhecimento e compartilhamento de significados, enquanto para computadores elas facilitam a compreensão das informações e um processamento mais extensivo, incentivando sua aplicação crescente na interoperabilidade semântica entre sistemas distribuídos. Para Abburu e Babu (2013), sistemas de Gestão do Conhecimento (e as eventuais ontologias que os representem) subdividem-se em componentes de aquisição, armazenamento e reutilização do conhecimento.

De acordo com Almeida (2006), o conhecimento organizacional é o componente fundamental do que denominou "memória organizacional", uma metáfora para representar o resultado do processo para, contextualmente, adquirir, representar, armazenar e recuperar o conhecimento dinâmico disperso na organização e obtido a partir de interações sociais e o suporte de um sistema tecnológico de informações. Para Berthelot et al. (2015), são três as motivações principais para a utilização de ontologias no ambiente organizacional:

1) A memória organizacional é, por natureza, heterogênea e fisicamente distribuída;

2) Os usuários das informações, que compõem a memória organizacional são, por natureza, heterogêneos e distribuídos pela organização;

3) As tarefas, como um todo, a serem realizadas sobre a memória organizacional, são, por natureza, heterogêneas e distribuídas.

A capacidade de representação das ontologias pode ser demonstrada através da KCRIO (LIN, 2013), uma ontologia desenvolvida para modelar atividades humanas a partir de conceitos e relacionamentos que envolvem conhecimento, capacitação, função, interação e organização, conforme a Figura 1.

De acordo com os conceitos (ou classes, representadas pelas elipses) e respectivas propriedades (representadas pelas setas) apresentados na Figura 1, uma organização qualquer (Organization) pode ser descrita através de sua estrutura organizacional, que se subdivide em agrupamentos funcionais ou suborganizações (como um departamento ou unidade de produção, por exemplo), que reproduzem em menor escala a própria organização a que pertencem, onde colaboradores de diferentes perfis (Role) e capacidades (Capacity) interagem (Interaction) formal ou casualmente (CasualInteraction e FormalizedInteraction) para produzir (DesignObject), estabelecendo assim processos que demandam conhecimentos específicos (Ontology, OntologyElement e Predicate) diante de um determinado contexto onde a organização se insere e atua.

$\mathrm{O}$ uso de ontologias pode apresentar vantagens e desvantagens. A representação progressiva do conhecimento disperso na organização, uniformização da linguagem organizacional e capacidade de realizar inferências são potencialidades benéficas, mas que precisam ser confrontadas com todos os problemas de retenção do conhecimento organizacional no contexto dinâmico atual, como, por exemplo, se questionar até que ponto é viável formalizar e atualizar frequentemente o conhecimento (ALMEIDA, 2006). 
Figura 1 - A ontologia K-CRIO

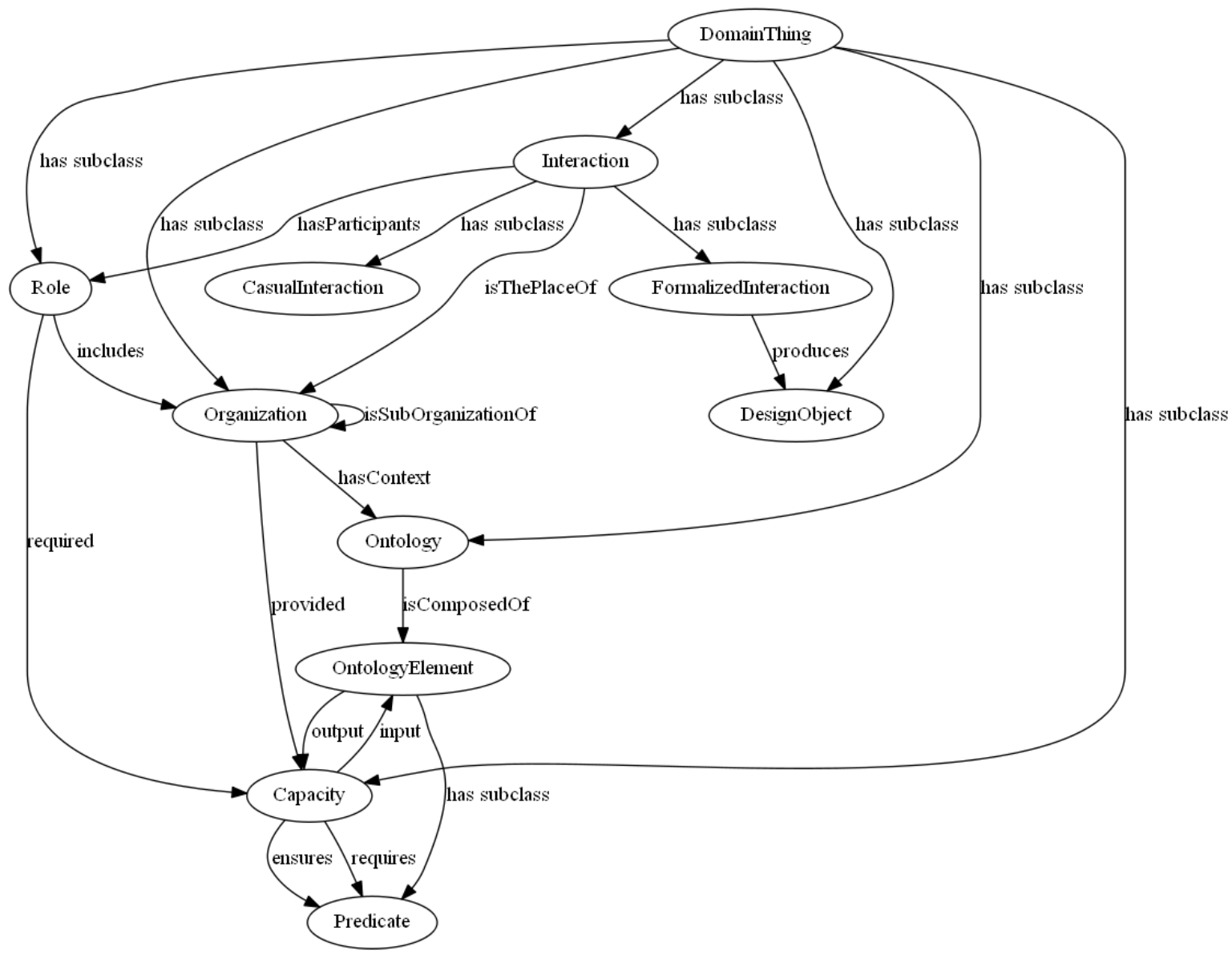

Fonte: adaptado de Lin (2013)

Conforme citado, uma das aplicações práticas das ontologias é a representação de processos de software. Segundo Sivanantham (2011), os principais ativos para o desenvolvimento de software são o conhecimento dos empregados e a cultura da organização, atividade na qual os principais impulsionadores para as empresas gerenciarem o conhecimento de forma eficaz são: reduzir o esforço gasto na aquisição de conhecimento necessário para a execução do projeto; melhorar a reutilização; reduzir a dependência de indivíduos para o sucesso do projeto, e melhorar a produtividade geral da equipe.

Um exemplo pertinente da aplicação de ontologias em projetos como um importante subsídio à Gestão do Conhecimento organizacional é apresentado por Lermen (2012), que desenvolveu uma ontologia que agrega ontologias representativas dos processos para Gestão de Projetos segundo o $\mathrm{PMI}^{\circledR}$ e os processos de três frameworks para desenvolvimento ágil de produtos, com o objetivo principal de, à semelhança de uma linha de produtos qualquer, possibilitar a Gestão do Conhecimento relacionado ao projeto de softwares, antes, durante e depois de sua criação.

A Figura 2 apresenta um mapa conceitual com a relação entre Gestão do Conhecimento, ontologias e projetos: 
Figura 2 - Mapa conceitual da relação entre Gestão do Conhecimento, ontologias e projetos

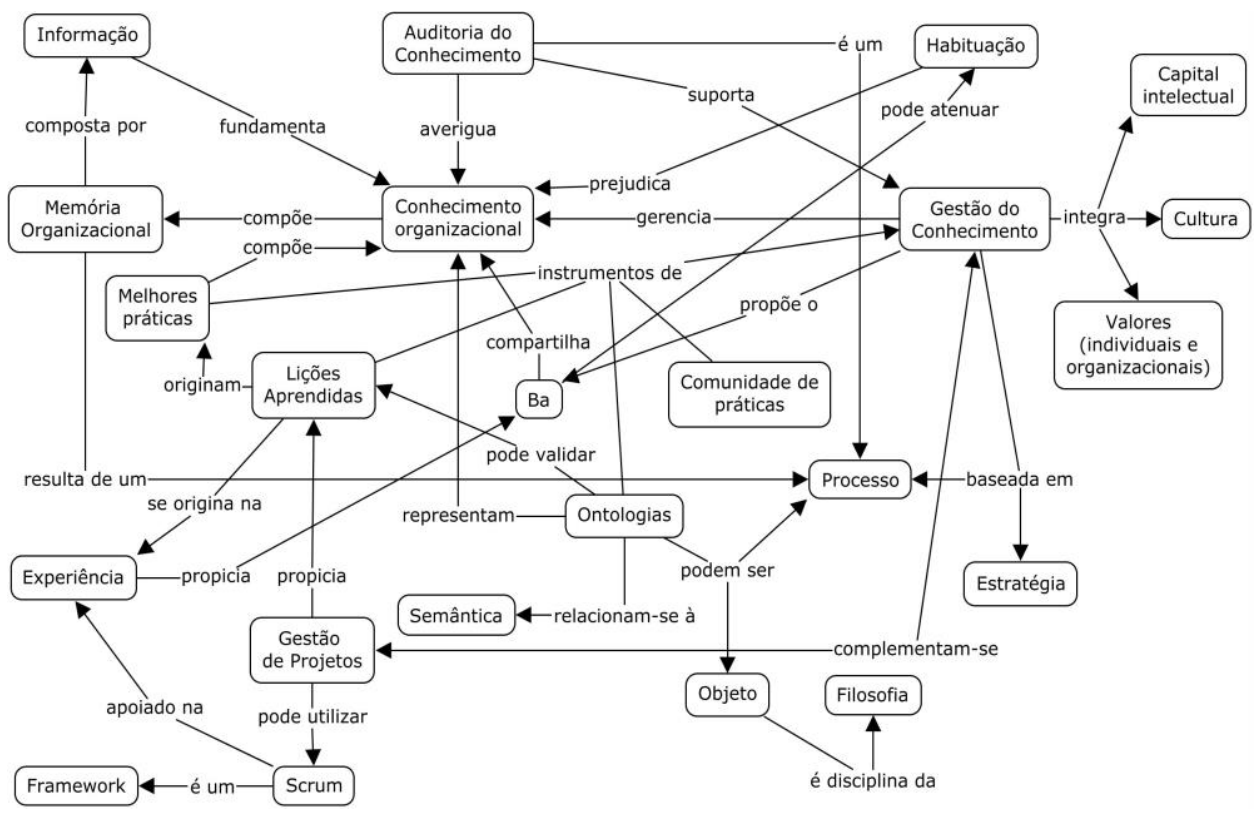

Fonte: os autores, utilizando o software Cmap Tools

A relação entre Gestão do Conhecimento, ontologias e projetos que se pretende aqui estabelecer (representada no mapa conceitual da Figura 2) é reforçada pelo acréscimo de um novo elemento, a Auditoria do Conhecimento. Segundo Marques (2017), a Auditoria do Conhecimento pode ser definida como um processo de investigação, identificação, análise, avaliação e revisão de recursos, conhecimentos e processos de conhecimento para apresentar a situação do conhecimento organizacional.

\section{O SCRUM E OS PROJETOS}

O Scrum foi concebido, elaborado e documentado por Jeff Sutherland, John Scumniotales e Jeff McKenna na empresa Easel Corporation em 1993, com base nos estilos de gerenciamento de jogos observados por Takeuchi e Nonaka e descritos no artigo "The New Product Develpment Game" (1986), onde observaram que equipes pequenas e multifuncionais (cross-functional) aumentam a eficiência e a produtividade no desenvolvimento de projetos. Influenciados pelo jogo de rubgy, Takeuchi e Nonaka concluíram que um estilo holístico, onde a equipe busca de forma integrada chegar ao gol com passes de bola, podia melhor servir às necessidades competitivas das organizações ao desenvolverem seus projetos. Em 1995, unindo-se a Sutherland, Ken Schwaber formalizou a definição de Scrum e ajudou a divulgá-lo para o desenvolvimento de software.

O Scrum é um framework, ou seja, uma estrutura de conhecimento constituída por um sistema de regras, ideias e crenças que favorecem a produção de algo. Segundo Schwaber e Sutherland (2017), enquanto framework o Scrum se configura como um processo composto de papéis, eventos, artefatos e regras para desenvolver e manter produtos, apoiado na transparência (ampla compreensão de suas atividades por todos os envolvidos no processo), inspeção (validação contínua de seus resultados) e adaptação (capacidade de realizar ajustes eventuais em relação ao produto e à equipe responsável pelo seu desenvolvimento), permitindo o emprego de outras técnicas e práticas que se revelem úteis a esta finalidade.

Os papéis exercidos no processo que fundamenta a aplicação do Scrum são Product Owner (o "proprietário" do produto a ser construído e responsável por seus requisitos e 
especificações junto ao Time de Desenvolvimento), Time de Desenvolvimento (Team), equipe encarregada de construir incremental e iterativamente o produto solicitado) e Scrum Master (o responsável pelo processo, por garantir o entendimento e a aplicação do Scrum perante as partes interessadas na entrega do produto planejado) (SCHWABER; SUTHERLAND, 2017).

As atividades do processo se constituem e desenvolvem em torno do Sprint, seu elemento constitutivo mais importante, caracterizado por ciclos regulares de duas a quatro semanas no máximo, ao término do qual uma versão parcial e incremental do produto é entregue para aprovação pelo Product Owner.

Assim, um processo do Scrum é formado basicamente por um ou mais Sprints, onde cada versão parcial entregue contém funcionalidades adicionais ou aprimoradas em relação à versão entregue no Sprint imediatamente anterior ao que se encerra. Esta talvez seja uma das explicações para a adoção do Scrum, por exemplo, no gerenciamento de projetos de tecnologia da informação, como o desenvolvimento de softwares (SCHWABER; SUTHERLAND, 2017).

Os Sprints originam quatro eventos formais cronologicamente conduzidos. O primeiro deles é a Reunião de Planejamento, onde são planejadas e organizadas as atividades a serem executadas dentro de um determinado Sprint. O segundo é a Reunião Diária, na qual o trabalho executado desde a última reunião diária é rapidamente inspecionado e se planeja o trabalho a executar nas próximas vinte quatro horas. O terceiro é a Revisão do Sprint, onde a versão entregue ao final do Sprint é inspecionada para se verificar seus incrementos em relação à versão anterior, adaptando-se a lista de atividades ainda a realizar, se for o caso. Por fim, a Retrospectiva do Sprint, que ocorre após sua finalização e na qual o Scrum Master e o Time de Desenvolvimento analisam o trabalho nela executado, apurando possíveis melhorias a serem implementadas na execução dos próximos Sprints (SCHWABER; SUTHERLAND, 2017).

Os artefatos entregues pelo processo representam o resultado das atividades executadas ou meios para se realizar a inspeção e adaptação. São eles o Backlog do Produto (uma lista de tudo aquilo que é necessário para construir o produto, a partir de seus requisitos e especificações), o Backlog do Sprint (a lista de atividades que serão executadas em um determinado Sprint para que seu objetivo seja atingido) e o Incremento (uma versão parcial do produto e que representa o somatório dos resultados das atividades executadas nos Sprints já finalizadas, incluindo a última). A atualização do status de cada item do Backlog do Produto ou Sprint é feita a partir do "Pronto", um atestado de que um determinado item atende a certas condições definidas pela equipe do processo, podendo ser então considerado como finalizado (SCHWABER; SUTHERLAND, 2017).

Ainda segundo Schwaber e Sutherland (2017) é importante mencionar que o Backlog do Produto persiste enquanto o produto existir, ou seja, ainda que o processo executado para sua construção tenha sido finalizado, acredita-se que aquele é passível de sofrer transformações diante das mudanças inerentes ao contexto organizacional onde se insere. Desta forma, ao longo do tempo, seus requisitos e especificações podem se revelar ultrapassados em sua finalidade original diante de novas necessidades organizacionais que se fizerem presentes, implicando, portanto, na atualização do Backlog do Produto mediante a concepção e elaboração de um novo processo neste sentido.

De acordo com Silva e Lovato (2016), a execução das atividades no Scrum tem forte apoio no empirismo, ou seja, acredita-se que o profissional inserido em seu processo melhor executa suas atividades quanto mais experiência prévia tiver em outros projetos, valorizandose mais seu espírito colaborativo e interações com ferramentas e menos as documentações (aqui entendidas como as inerentes ao produto e à execução do processo em si). Trata-se, portanto, de um framework que se preocupa essencialmente com o conhecimento tácito e suas possíveis formas de socializá-lo entre os participantes do processo.

Perspectivas em Gestão \& Conhecimento, João Pessoa, v. 9, n. 1, p. 82-100, jan./abr. 2019 
Segundo o $\mathrm{PMI}^{\circledast}$ (2018), um projeto é um esforço temporário realizado para criar um produto, serviço ou resultado exclusivo e, sendo assim, a julgar por seus objetivos e características aqui apresentados, pode-se dizer que uma aplicação do Scrum é um projeto. Neste sentido, para Ferenhof, Forcellini e Varvakis (2013) projetos oferecem possibilidades de aprendizado durante todo o seu ciclo de vida a qualquer indivíduo que atue na execução de alguma de suas atividades. Da mesma forma, Terzieva (2014) acredita que, pelo fato de não serem exatamente iguais, projetos representam oportunidades de adquirir novos conhecimentos em nível individual e organizacional. Portanto, a adoção do Scrum em projetos também oferece esta possibilidade.

O $\mathrm{PMI}^{\circledR}(2018)$ concebe o gerenciamento de projetos a partir de processos, com suas entradas, ferramentas e técnicas e saídas; uma das entradas mais importantes para as atividades de planejamento são os ativos de processos organizacionais, que incluem qualquer artefato, prática ou conhecimento que possa ser usado para gerenciar o projeto, como as bases de conhecimento oriundas do registro de lições aprendidas e outras informações históricas. Ainda segundo o $\mathrm{PMI}^{\circledR}$ (2013), os ativos de processos organizacionais podem ser atualizados ao longo do ciclo de vida do projeto de acordo com a necessidade, uma prática recomendada por outra referência mundial em gerenciamento de projetos, a IPMA ${ }^{\circledR}$ (2006), que reconhece o desenvolvimento de uma base de conhecimento utilizável e atualizada sobre o assunto como uma competência chave para um efetivo gerenciamento de projetos pelas organizações.

A partir das visões acima descritas sobre o desenvolvimento de uma base de conhecimento em gerenciamento de projetos, vale ressaltar que, se para Ferenhof, Forcellini e Varvakis (2013), segundo a Gestão do Conhecimento, "toda e qualquer experiência é conhecimento, e este deve ser explicitado, compartilhado e disseminado para agregar valor às pessoas e organizações", e a ideia central destas visões aponta na direção da utilidade. Segundo esta concepção, portanto, o registro de lições aprendidas em projetos deve refletir a busca por um sentido que legitime um possível novo conhecimento no contexto do gerenciamento de projetos praticado por uma determinada organização, aprimorando-o.

\section{APURAÇÃO E REGISTRO DE LIÇÕES APRENDIDAS}

Uma das formas de explicitar o conhecimento numa organização é registrar as lições aprendidas. Trata-se de armazenar, se possível em um meio físico, para facilitar a busca e a disseminação de informações, as experiências que, de algum modo, trouxeram um ensinamento relevante. Para Rautenberg (2009), as lições aprendidas são experiências (bem sucedidas ou não) armazenadas como conhecimento organizacional e disponibilizadas explicitamente para consulta e aprendizado dos indivíduos. Segundo Veronese (2014), há diferentes métodos de apuração de lições aprendidas, aplicáveis em atividades que demandem a organização do conhecimento, como os projetos, de acordo com o apresentado no Quadro 1:

Quadro 1 - Métodos de apuração de lições aprendidas

\begin{tabular}{|c|c|c|}
\hline \multirow{2}{*}{ MÉTODO } & \multicolumn{2}{|c|}{ CRITÉRIOS } \\
\cline { 2 - 3 } & CARACTERÍSTICAS & APLICABILIDADE \\
\hline $\begin{array}{c}\text { 1. Avaliação pós- } \\
\text { projeto }\end{array}$ & $\begin{array}{c}\text { Elaboração, de maneira formal e não cooperativa, de um } \\
\text { documento que contenha o registro de eventuais experiências } \\
\text { relevantes ocorridas no projeto, que podem ser obtidas a } \\
\text { partir de sua própria equipe ou de sua documentação }\end{array}$ & $\begin{array}{c}\text { Após a conclusão } \\
\text { do projeto }\end{array}$ \\
\hline 2. Apreciação pós- & Grupo de trabalho composto por profissionais não envolvidos & Cerca de dois \\
\hline
\end{tabular}

Perspectivas em Gestão \& Conhecimento, João Pessoa, v. 9, n. 1, p. 82-100, jan./abr. 2019 


\begin{tabular}{|c|c|c|}
\hline projeto & $\begin{array}{l}\text { na execução de um projeto, e que assim se constituem para } \\
\text { avaliá-lo (através da análise de sua documentação e } \\
\text { entrevistas) e produzir um relatório a ser submetido à equipe } \\
\text { do projeto e um conselho de avaliação; o resultado final é uma } \\
\text { coleção de casos }\end{array}$ & $\begin{array}{l}\text { anos após a } \\
\text { conclusão do } \\
\text { projeto }\end{array}$ \\
\hline $\begin{array}{l}\text { 3. Comunidade de } \\
\text { prática }\end{array}$ & $\begin{array}{c}\text { Grupo informal e autogestionado de indivíduos de interesse } \\
\text { comum de aprendizado sobre um determinado assunto, onde } \\
\text { um líder atua como facilitador na captura, organização e } \\
\text { disseminação do conhecimento obtido através do } \\
\text { compartilhamento de ferramentas, experiências e } \\
\text { instrumentos }\end{array}$ & Durante o projeto \\
\hline $\begin{array}{l}\text { 4. Avaliação após } \\
\text { ação }\end{array}$ & $\begin{array}{l}\text { Reuniões para apurar erros e acertos ocorridos no projeto, } \\
\text { com o apoio de um facilitador e questionário básico onde os } \\
\text { participantes são convidados a compartilhar suas experiências }\end{array}$ & $\begin{array}{l}\text { Após a conclusão } \\
\text { de uma ação } \\
\text { relevante no } \\
\text { projeto }\end{array}$ \\
\hline $\begin{array}{l}\text { 5. Reunião de } \\
\text { retrospectiva }\end{array}$ & $\begin{array}{c}\text { Reuniões periódicas para apurar se objetivos e expectativas } \\
\text { foram atendidos, com a participação de um facilitador que se } \\
\text { encarrega posteriormente de eliminar obstáculos à melhoria } \\
\text { contínua de curto prazo }\end{array}$ & $\begin{array}{l}\text { Após a conclusão } \\
\text { de uma fase do } \\
\text { projeto }\end{array}$ \\
\hline 6. Microartigo & $\begin{array}{l}\text { Documento informal e contextual, curto (meia página) e que } \\
\text { relata uma experiência sob a forma de } 1 \text { tópico, com } \\
\text { introdução e palavras-chave para indexação }\end{array}$ & $\begin{array}{c}\text { Após a conclusão } \\
\text { de uma atividade } \\
\text { ou experiência } \\
\text { relevante } \\
\text { ocorrida durante } \\
\text { o projeto, ou após } \\
\text { a conclusão deste }\end{array}$ \\
\hline $\begin{array}{l}\text { 7. História de } \\
\text { aprendizagem }\end{array}$ & $\begin{array}{l}\text { Descrição cronológica dos principais eventos do projeto } \\
\text { (sobretudo o conhecimento tácito a eles relacionado) a partir } \\
\text { das observações sobre as experiências neles vivenciadas, } \\
\text { mediante entrevistas e reuniões de discussão }\end{array}$ & $\begin{array}{l}\text { Após a conclusão } \\
\text { do projeto }\end{array}$ \\
\hline $\begin{array}{l}\text { 8. Documentação } \\
\text { leve de } \\
\text { experiências }\end{array}$ & $\begin{array}{c}\text { Apuração de experiências obtidas junto à equipe do projeto, } \\
\text { que são coletadas mediante templates próprios, apresentadas } \\
\text { e compartilhadas como histórias }\end{array}$ & $\begin{array}{l}\text { Após a conclusão } \\
\text { de uma atividade } \\
\text { relevante } \\
\text { ocorrida durante } \\
\text { o projeto }\end{array}$ \\
\hline $\begin{array}{l}\text { 9. Contexto } \\
\text { compartilhado } \\
\qquad(B a)\end{array}$ & $\begin{array}{l}\text { Um lugar (físico e/ou virtual) onde o conhecimento é } \\
\text { contextualmente elaborado, compartilhado e utilizado por } \\
\text { uma comunidade diversificada e altamente interativa }\end{array}$ & Durante o projeto \\
\hline 10. Journaling & $\begin{array}{c}\text { Narração reflexiva, crítica e apoiada por um redator e } \\
\text { questionário, sobre experiências ou eventos específicos de } \\
\text { aprendizagem }\end{array}$ & $\begin{array}{l}\text { Durante o } \\
\text { projeto, duas } \\
\text { vezes por semana }\end{array}$ \\
\hline 11. $4 A L L$ & $\begin{array}{l}\text { Reunião de agenda e foco definidos por um moderador, para } \\
\text { apurar excelências e desafios no projeto, a partir dos quais } \\
\text { serão propostas ações corretivas e melhorias }\end{array}$ & $\begin{array}{c}\text { Após a conclusão } \\
\text { do projeto }\end{array}$ \\
\hline
\end{tabular}

Fonte: adaptado de Veronese (2014)

A partir do Quadro 1, verifica-se que dos onze métodos de apuração de lições aprendidas apresentados, oito (métodos 1, 3, 4, 6, 7, 8, 9 e 10, ou 73\% do total) apoiam-se explicitamente nas experiências vivenciadas, num primeiro momento; os métodos 2, 5 e 11

Perspectivas em Gestão \& Conhecimento, João Pessoa, v. 9, n. 1, p. 82-100, jan./abr. 2019 
utilizam-se também de reuniões e entrevistas, nas quais se pode pressupor que experiências vivenciadas no projeto sejam compartilhadas. Importante dizer que nenhum dos métodos menciona ou sugere qualquer legitimação de um possível aprendizado oriundo de experiências vivenciadas, antes de efetuar o respectivo registro como uma lição aprendida.

Segundo a Asian Productivity Organization (APO, 2010), a Gestão do Conhecimento se compõe de cinco processos (Identificar, Criar, Armazenar, Compartilhar e Aplicar conhecimento), onde cada um possui listas sugeridas de métodos e ferramentas para apoiar suas respectivas atividades, nas quais métodos de apuração de lições aprendidas figuram com diferentes denominações, conforme apresentado no Quadro 2:

Quadro 2 - Distribuição de métodos de apuração de lições aprendidas segundo a Gestão do Conhecimento

\begin{tabular}{|c|c|c|}
\hline \multicolumn{3}{|c|}{$\begin{array}{c}\text { MÉTODOS DE APURAÇÃO DE LIÇÕES APRENDIDAS E ETAPAS } \\
\text { DA GESTÃO DO CONHECIMENTO }\end{array}$} \\
\hline MÉTODO & CARACTERÍSTICAS & ETAPA \\
\hline $\begin{array}{l}\text { 1. Aprendizagem e } \\
\text { captura de ideais }\end{array}$ & $\begin{array}{l}\text { Um aspecto chave da Gestão do } \\
\text { Conhecimento e que procura coletiva e } \\
\text { sistematicamente desenvolver um guia de como } \\
\text { fazer uma determinada atividade }\end{array}$ & Criar conhecimento \\
\hline $\begin{array}{l}\text { 2. Revisão de } \\
\text { aprendizado }\end{array}$ & $\begin{array}{c}\text { Técnica utilizada por uma equipe de projeto para } \\
\text { auxiliar o aprendizado individual ou da própria } \\
\text { equipe após um evento significativo ocorrido } \\
\text { durante o projeto }\end{array}$ & $\begin{array}{l}\text { Criar conhecimento } \\
\text { Armazenar conhecimento } \\
\text { Compartilhar conhecimento }\end{array}$ \\
\hline $\begin{array}{l}\text { 3. Comunidade de } \\
\text { prática }\end{array}$ & $\begin{array}{l}\text { Grupo (formado intencional ou } \\
\text { espontaneamente) que compartilha o interesse } \\
\text { por algo que faz e deseja aprender a fazer melhor } \\
\text { a partir de interações regulares entre seus } \\
\text { indivíduos para desenvolver habilidades, } \\
\text { conhecimento e especializações }\end{array}$ & $\begin{array}{l}\text { Identificar conhecimento } \\
\text { Criar conhecimento } \\
\text { Armazenar conhecimento } \\
\text { Compartilhar conhecimento } \\
\text { Aplicar conhecimento }\end{array}$ \\
\hline $\begin{array}{l}\text { 4. Avaliação após } \\
\text { ação }\end{array}$ & $\begin{array}{c}\text { Técnica para apurar lições aprendidas após a } \\
\text { conclusão de um evento marcante do projeto ou } \\
\text { após a conclusão deste, através de uma } \\
\text { discussão informal entre os membros da equipe } \\
\text { do projeto }\end{array}$ & $\begin{array}{l}\text { Criar conhecimento } \\
\text { Armazenar conhecimento } \\
\text { Compartilhar conhecimento }\end{array}$ \\
\hline 5. Storytelling & $\begin{array}{l}\text { Apresentação, por um indivíduo e no formato de } \\
\text { uma estória a ser contada, de uma vivência } \\
\text { significativa que representou uma aprendizagem } \\
\text { para ele }\end{array}$ & Compartilhar conhecimento \\
\hline
\end{tabular}

Fonte: adaptado de APO (2010)

A partir do Quadro 2, percebe-se que em uma comunidade de prática (método 3) as oportunidades de apuração de lições aprendidas podem ocorrer em todas as etapas da Gestão do Conhecimento, enquanto a Revisão de aprendizado (método 2) e Avaliação após ação (método 4) assemelham-se à Retrospectiva da Sprint ou ao menos podem ser executadas nesta atividade. Por fim, a Aprendizagem e captura de ideias (método 1) representa a construção gradativa de uma base de conhecimento sobre as melhores práticas organizacionais.

Para Martinez (2013), as lições aprendidas são um importante subsídio para a definição de ações eventuais que se fazem necessárias para a efetividade da organização, as

Perspectivas em Gestão \& Conhecimento, João Pessoa, v. 9, n. 1, p. 82-100, jan./abr. 2019 
chamadas melhores práticas, que representam resultados normalmente favoráveis oriundos de uma elaboração baseada na vivência de experiências sejam ou não bem-sucedidas. Ressalta o autor, entretanto, a dificuldade em identificá-las adequadamente diante de questionamentos como, por exemplo, quem é capaz de identificar uma atividade como melhor prática, como as organizações podem garantir que elas de fato agregam valor, e quais os critérios para se atestar uma atividade como melhor prática. Pela relação estabelecida entre melhores práticas e lições aprendidas, acredita-se aqui que tais questionamentos também se aplicam a estas.

No Scrum, cada Sprint oferece oportunidades de experiências individuais e coletivas e, muito embora o Scrum Master seja o responsável pela execução do processo (e do projeto que a ele se possa associar, em última análise), não deve ser o único responsável pela apuração e registro de lições aprendidas: alinhado à natureza coletiva do framework, isto deve ser resultado do esforço de todos os seus participantes. Assim, ao Scrum Master principalmente recomenda-se a atribuição de estimular a apuração de lições aprendidas a partir da identificação de lições candidatas ao registro. Por outro lado, o Product Owner pode atuar também neste sentido, uma vez que, como o Backlog do Produto pode ser acrescido de novas funcionalidades após o encerramento do projeto que originou a última versão do respectivo produto, é parte interessada no aprimoramento do gerenciamento de projetos.

O desenvolvimento de uma ontologia específica é o que pode tornar candidata uma suposta lição aprendida, por representar um domínio de conhecimento que pode legitimá-la ou não. Diante de uma ontologia estabelecida, o registro de uma lição aprendida representa um indicativo da pertinência do conhecimento que se busca oferecer, a legitimação perante a comunidade que a estabeleceu e que desta se utiliza para aprimorar seu próprio conhecimento.

\section{POSSIBILIDADES DE USO DE ONTOLOGIAS NA APLICAÇÃO DO SCRUM}

Os tópicos anteriores buscaram apresentar resumidamente os principais elementos pertinentes à Gestão do Conhecimento, estabelecendo uma relação complementar desta com o gerenciamento de projetos enquanto discorre sobre dois importantes instrumentos de aprimoramento do conhecimento organizacional, as lições aprendidas e ontologias. Em seguida, aventou-se a utilização de ontologias como suporte à apuração e registro de lições aprendidas durante a aplicação do Scrum em projetos quaisquer. Neste sentido, portanto, apresentam-se a seguir algumas possibilidades de uso de ontologias.

A partir do que se descreveu sobre o Scrum, acredita-se que se principalmente a Sprint propicia a vivência de experiências significativas do ponto de vista individual e organizacional, a Retrospectiva da Sprint (e, em menor grau, as demais reuniões que o framework recomenda) permite a apuração de eventuais lições aprendidas a elas relacionadas e candidatas a posterior registro caso sejam legitimadas; nem tudo o que se vivencia pode ser considerado útil à organização, necessitando-se, portanto, estabelecer critérios de aprovação para atestar uma experiência como lição aprendida.

Para a IPMA ${ }^{\circledR}$ (2006) e o $\mathrm{PMI}^{\circledast}$ (2018), o sucesso de um projeto passa pela capacidade de se atingir seus objetivos cumprindo o escopo, custo e prazo (tempo) planejados, uma perspectiva que pode ser estendida aos projetos conduzidos a partir da aplicação do Scrum e pode servir como um ponto de partida para se atestar ou não uma lição como aprendida. Temse então que estas três variáveis (juntas ou separadamente) podem ser usadas para identificar se uma lição aprendida candidata a registro de fato o será, considerando que organizações que executam projetos tenham o interesse em elaborar uma base de conhecimento no assunto.

Tempo é um fator crucial de sucesso na aplicação do Scrum e, por consequência, devese buscar a eficácia ao estimar a duração das atividades a serem executadas nos projetos que

Perspectivas em Gestão \& Conhecimento, João Pessoa, v. 9, n. 1, p. 82-100, jan./abr. 2019 
dele se utilizam. A experiência previamente adquirida neste sentido não deve ser negligenciada, mas considerada, enquanto a utilização de ferramentas e técnicas próprias pode ser de grande valia para legitimar as estimativas. Uma destas técnicas é a Análise por Pontos de Função (APF), que permite estimar através de métricas específicas o esforço para executar uma determinada tarefa a partir das funcionalidades a ela associadas. A partir da APF e de outras técnicas semelhantes, métricas também podem ser elaboradas para se estimar custos de recursos humanos e materiais envolvidos na execução destes projetos.

Por outro lado, cada aplicação do Scrum tem por objetivo construir sob a forma de um projeto um novo produto ou aprimorar um já existente, a partir das especificações fornecidas pelos solicitantes e administradas pelo Product Owner, a quem se atribui a responsabilidade de garantir que o mesmo, durante seu ciclo de vida, atenda as necessidades para as quais foi concebido e elaborado. Isto demanda a disponibilização de informações atualizadas a seu respeito, bem como sobre possíveis interações com outros produtos, algo que se torna cada vez mais necessário à medida que aumenta a complexidade das atividades organizacionais e, por consequência, se sucedem a execução de novos projetos a este respeito.

Por fim, o Scrum, como qualquer framework ou metodologia, necessita ter seus objetivos, características e procedimentos disponibilizados entre seus usuários, favorecendo seu aprendizado e, portanto, aceitação e utilização; ele próprio é um produto suscetível a aprimoramentos, demandando eventuais atualizações. Por outro lado, as organizações não costumam incorporar integralmente em suas atividades o que é prescrito por frameworks e metodologias, realizando então adaptações. Assim, para evitar questionamentos, torna-se importante descrever exatamente de que forma a organização incorporou e utiliza o Scrum.

Acredita-se que as possibilidades acima citadas se relacionam com os elementos da ontologia K-CRIO (Figura 1), sendo, assim, passíveis de serem implementadas para aplicação em projetos que se utilizem do Scrum. Há, entretanto, possíveis lacunas nesta ontologia e que dizem respeito a apuração e registro de lições aprendidas. Primeiro, embora a apuração em si esteja representada pela classe Interaction, não há uma clara representação de sua contribuição (especificamente, da vivência de experiências advindas da interação entre pessoas) para a capacitação dos colaboradores organizacionais. E segundo, se o conhecimento organizacional é contextual, então seu aprimoramento deve observar um determinado domínio de interesses e, assim, se recomenda a validação prévia de uma lição aprendida, uma ação não representada na ontologia.

Assim, uma decorrência deste estudo é apresentar o que se considera um aprimoramento da ontologia K-CRIO, qual seja sugerir, para preencher as lacunas citadas, a inclusão de duas novas propriedades (destacadas em pontilhado): em relação à primeira lacuna, a inclusão da propriedade contributes na classe Interaction, enquanto na segunda, a inclusão da propriedade validates na classe Role, conforme demonstrado na Figura 3 :

Perspectivas em Gestão \& Conhecimento, João Pessoa, v. 9, n. 1, p. 82-100, jan./abr. 2019 
Figura 3 - Proposta de alterações na ontologia K-CRIO

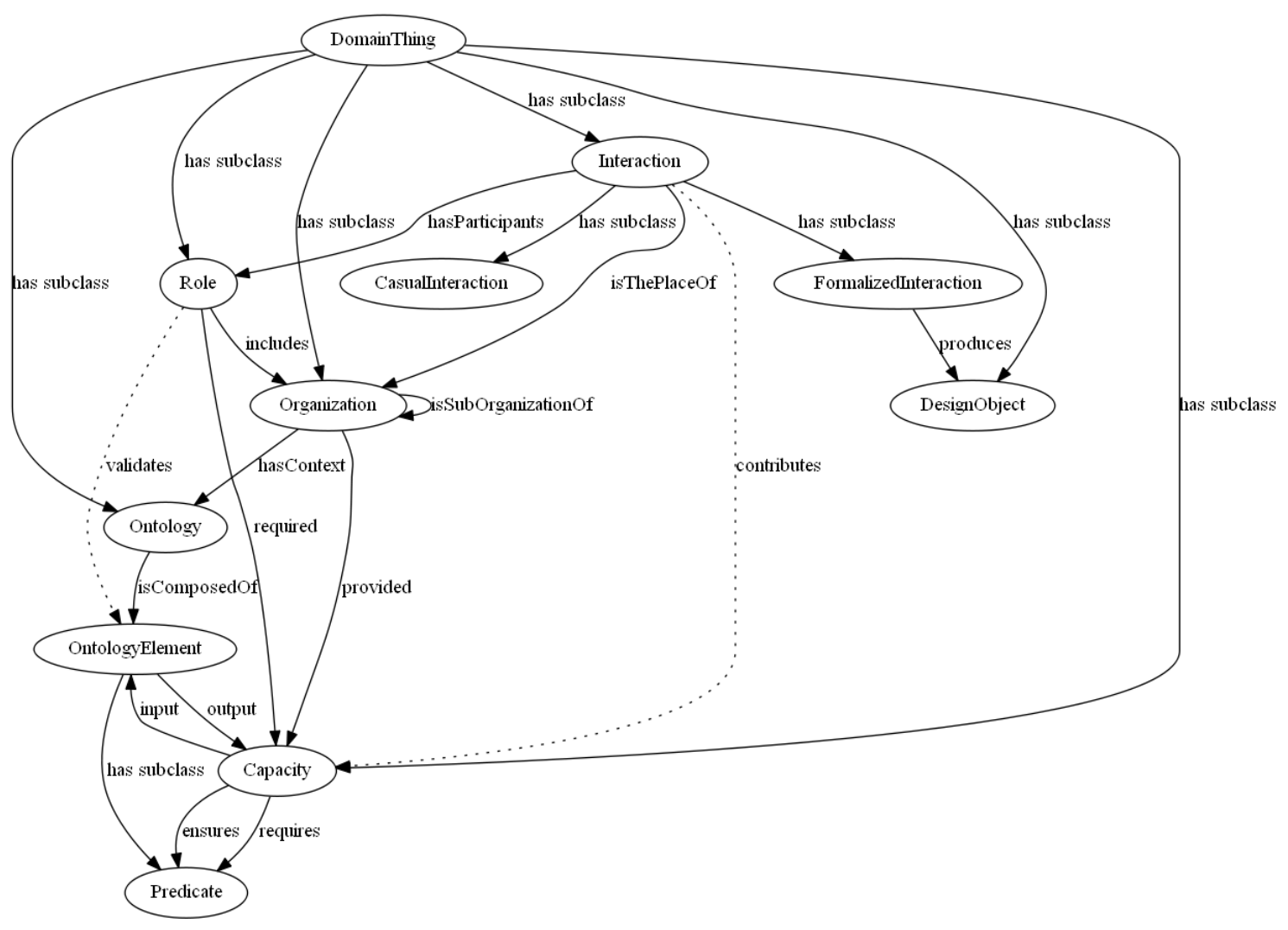

Fonte: os autores

\section{CONSIDERAÇÕES FINAIS}

A partir de seus objetivos, características e procedimentos, as gestões do conhecimento e de projetos não são atividades organizacionais isoladas, mas complementares e mesmo compartilhadas em alguns pontos, como no incentivo ao registro de lições aprendidas e uso de ontologias para a organização e representação do conhecimento organizacional, além de intrinsecamente relacionadas à memória organizacional e auditoria do conhecimento. Desta forma, recomenda-se que as atividades relacionadas a estes quatro conceitos sejam percebidas e gerenciadas de maneira integrada, com suas ameaças e oportunidades referentes ao aprimoramento e compartilhamento do conhecimento.

Dentre estas ameaças, uma das mais relevantes é a Habituação, que para ser enfrentada depende sobretudo da criação de um ambiente baseado no cuidado mútuo (Mutual Caring) para que seus integrantes adquiram a confiança necessária para romper este círculo vicioso, permitindo a fluidez do conhecimento entre eles. Ao que parece, o $B a$ se presta a oferecer isto, e assim se acredita que nele a apuração e registro de lições aprendidas são favorecidos. Por outro lado, uma vez que o Scrum se preocupa essencialmente com o conhecimento tácito e suas possíveis formas de socializá-lo entre os participantes de seu processo, por analogia pode-se dizer que seu contexto é semelhante ao do $B a$ em seus objetivos e características.

Neste cenário, as ontologias podem representar uma oportunidade de aprimoramento e compartilhamento do conhecimento organizacional referente ao Scrum e, uma vez que o mesmo em geral é aplicado sob a forma de um projeto, à própria Gestão de Projetos. Conforme a ontologia K-CRIO apresentou, são instrumentos de Gestão do Conhecimento que 
podem ser aplicados a quaisquer organizações, favorecendo o aprimoramento a partir das interações (ou experiências) entre seus integrantes e da validação, perante um determinado domínio de conhecimento, de conteúdos nelas obtidos - como, por exemplo, as lições aprendidas; por se tratarem de modelos formais e computacionais de representação, tornamse uma referência acessível, facilitando o compartilhamento do conhecimento que reúnem.

Uma decorrência da temática tratada neste artigo mostra a capacidade de organização e representação do conhecimento oferecidas pelas ontologias, qual seja o aprimoramento sugerido à ontologia K-CRIO sob a forma da inclusão de duas novas propriedades: a primeira, para representar a validação, por parte dos integrantes de uma organização, da ontologia que utiliza, e a segunda, para representar a contribuição das interações entre os integrantes de uma organização para capacitação individual e coletiva; ambas refletem parte do referencial teórico aqui apresentado sobre Gestão do Conhecimento.

Uma aplicação típica do Scrum oferece possibilidades de apuração de lições aprendidas e do uso de ontologias como suporte aos respectivos métodos de registro. A Sprint propicia a vivência de experiências significativas, enquanto a Retrospectiva da Sprint permite a apuração de eventuais lições aprendidas candidatas a registro, caso sejam legitimadas. E uma vez que o sucesso de um projeto passa pela capacidade de se atingir seus objetivos cumprindo o escopo, custo e prazo planejados, estas variáveis podem servir como um ponto de partida para se atestar ou não uma lição como aprendida. Assim, a utilização de ferramentas e técnicas próprias pode ser útil para legitimar estimativas para estas variáveis, como a Análise por Pontos de Função (APF), que pode ter o conhecimento a ela associada representado através de uma ontologia, bem como o backlog dos produtos desenvolvidos.

Um ponto a destacar diz respeito às subdivisões em componentes de aquisição, armazenamento e reutilização inerentes aos sistemas de Gestão do Conhecimento. Uma aplicação típica do Scrum valoriza mais o conhecimento tácito que o explícito, priorizando a realização das atividades em detrimento da elaboração de sua respectiva documentação; implicitamente, isto pode trazer riscos de prejuízos à utilização destes componentes, o que comprometeria a eficácia de seus respectivos sistemas. A partir da temática aqui apresentada, acredita-se que esta perspectiva seja um estímulo à elaboração de pesquisas futuras.

\section{REFERÊNCIAS}

ABBURU, S.; BABU, G. S. A framework for ontology based knowledge management. International Journal of Soft Computing and Engineering, v. 3, n. 3, p. 21-25, 2013.

ASIAN PRODUCTIVITY ORGANIZATION (APO). Knowledge management tools and techniques manual. Asian Productivity Organization, 2010.

ALMEIDA, M. B. Um modelo baseado em ontologias para representação da memória organizacional. 2006. Tese (Doutorado em Ciência da Informação) - Universidade Federal de Minas Gerais, 2006.

BERTHELOT, L. et al. CoMMA Corporate Memory Management through Agents Corporate Memory Management through Agents: The CoMMA project final report. [Research Report] Inria. 2002, p. 61. Disponível em: https://hal.inria.fr/hal-01146259/document. Acesso em: 24 nov. 2018.

BLOEHDORN, S. et al. Ontology evolution. In: DAVIES, J. et al. (eds). Semantic Web Technologies: trends and research in ontology-based systems. [S.n; s.I.], 2006. p. 51-70.

Perspectivas em Gestão \& Conhecimento, João Pessoa, v. 9, n. 1, p. 82-100, jan./abr. 2019 
CHOO, C. Wei.; ALVARENGA NETO, R. C. D. de. Beyond the Ba: managing enabling contexts in knowledge organizations, Journal of Knowledge Management, v.14, n. 4, p.592-610, 2010.

DEVEDZIC, V. Understanding ontological engineering. Communications of the ACM, v. 45, n. 4, p. 136-144, 2002.

FERENHOF, H. A.; FORCELLINI, F. A.; VARVAKIS, G. Lições aprendidas: agregando valor ao gerenciamento de projetos. Revista de Gestão e Projetos - GeP, São Paulo, v. 4, n. 3, p. 197209, set./dez. 2013.

HANDZIC, M.; DURMIC, N. Knowledge Management, Intellectual Capital and Project Management: Connecting the Dots. The Electronic Journal of Knowledge Management, v. 13, n. 1,2015 , p. 51-61.

INTERNATIONAL PROJECT MANAGEMENT ASSOCIATION (IPMA). ICB-IPMA Competence Baseline. International Project Management Association. 2006.

JUGDEV, K.; WISHART, P. Mutual caring - resolving habituation through awareness: Supporting Meaningful Learning From Projects. Project Management Journal, v. 45, n. 2, p. 66-82, 2014.

KEYES, J. Knowledge management, business intelligence, and content management: the IT Practitioner's Guide. Auerbach Publications, 2006.

LERMEN, M. Molps: uma ontologia para definição de linha de produto de software para gerência de projeto com metodologias ágeis. 2012. Dissertação (Mestrado em Computação Aplicada) - Universidade do Vale do Rio dos Sinos, 2012.

LIN, Y. An organitazional ontology for multiagent-based Enterprise Process modeling and automation. 2013. Tese (Doutorado). Université de Technologie de Belfort-Montbeliard, 2013.

MAIER, R. Knowledge management systems information and communication technologies for knowledge management. Springer, 2007.

MAIER, R. Modeling knowledge work for the design of knowledge infrastructures. Journal of Universal Computer Science, v. 11, n. 4, p. 429-451, 2005.

MARTINEZ, A. C. P. Gestão do conhecimento: gerenciamento das lições aprendidas em projetos de engenharia para a indústria de óleo e gás. 2013. Dissertação (Mestrado em Química) - Universidade Federal do Rio de Janeiro, 2013.

NISSEN, M. E. Harnessing knowledge dynamics. Idea Group Inc., 2006.

NONAKA, I.; KONNO, N. The Concept of "Ba": building a foundation for knowledge creation. California Management Review, v. 40, n.3, p. 40-54, Spring 1998.

OLIVEIRA, A. B. F de; WERNECK, V. M. B. Ontologias. Cadernos do IME: Série Informática, Rio de Janeiro, v. 15, p. 7-13, dez. 2003.

PROJECT MANAGEMENT INSTITUTE (PMI). Um guia do conhecimento em gerenciamento de projetos (Guia $\mathbf{P M B O K}^{\circledR}$ ). 6 ed. Project Management Institute, Inc., 2018.

Perspectivas em Gestão \& Conhecimento, João Pessoa, v. 9, n. 1, p. 82-100, jan./abr. 2019 
RAUTENBERG, S. Modelo de conhecimento para mapeamento de instrumentos da gestão do conhecimento e de agentes computacionais da engenharia do conhecimento baseado em ontologias. 2009. Tese (Doutorado em Engenharia de Produção e Gestão do Conhecimento). Universidade Federal de Santa Catarina, Florianópolis, 2009.

SAITO, A.; UMEMOTO, K.; IKEDA, M. A strategy-based ontology of knowledge management technology. Journal of Knowledge Management, v. 11, n. 1, p. 97-114, 2007.

SANTIAGO JÚNIOR, J. R. S. O processo de lições aprendidas em projeto, o maior dos desafios de uma organização. Disponível em: https://vanzolini.org.br/weblog/2014/06/11/o-processode-licoes-aprendidas-em-projeto-o-maior-dos-desafios-de-uma-organizacao/.

Acesso em: 25 out. 2018.

SCHWABER, K; SUTHERLAND, J. Guia do Scrum ${ }^{M R}$ - um guia definitivo para o Scrum: as regras do jogo. 2017. Disponível em: https://www.scrumguides.org/docs/scrumguide/v2017/2017Scrum-Guide-Portuguese-Brazilian.pdf. Acesso em: 21 nov. 2018.

SILVA, E. C. da.; LOVATO, L. A. Scrum framework: efficiency in software projects. Revista de Gestão e Projetos - GeP. São Paulo, v. 7, n. 2, p. 1-15, mai/ago. 2016.

SHARIF, M. N. A. et al. Facilitating Knowledge Sharing Through Lessons Learned System. Journal of Knowledge Management Practice, March 2005.

SIVANANTHAM, V. Knowledge management in agile projects. Cognizant's Advanced Solutions Group, NJ, USA, 2011.

SOUSA, N. M.; COSTA, C. J.; APARICIO, M. Ba: Um fator determinante no uso de sistemas de gestão do conhecimento. RISTI, Porto, n. 22, p. 1-19, jun. 2017. Disponível em: http://www.scielo.mec.pt/scielo.php?script=sci arttext\&pid=S1646-

98952017000200002\&lng=pt\&nrm=iso. Acesso em: 23 nov. 2018.

TAKEUCHI, H.; NONAKA, I. The new new product development game. Harvard Business Review, January 1986. Disponível em: https://hbr.org/1986/01/the-new-new-productdevelopment-game. Acesso em 2 de dez. De 2018.

TELES, $\quad$ V. M. Manifesto ágil. Disponível em: https://www.desenvolvimentoagil.com.br/xp/manifesto agil. Acesso em: 2 dez. 2018.

TERZIEVA, M. Project knowledge management: how organizations learn from experience. Procedia Technology, v. 16, p. 1086-1095, 2014.

TSUI, E. The role of IT in KM: where are we now and where are we heading? Journal of Knowledge Management, v. 9, n. 1, p. 3-6, 2005.

VERONESE, G. S. Métodos para captura de lições aprendidas: em direção a uma melhoria contínua na gestão de projetos. Revista de Gestão e Projetos - GeP. São Paulo, v. 5, n. 1, p. 71-83, jan./abr. 2014.

Perspectivas em Gestão \& Conhecimento, João Pessoa, v. 9, n. 1, p. 82-100, jan./abr. 2019 
VON KROGH, G.; ICHIJO, K.; NONAKA, I. Facilitando a criação do conhecimento: reinventando a empresa com o poder da inovação contínua. Rio de Janeiro: Campus, 2001.

WALTZ, E. Knowledge management in the intelligence enterprise. Artech House, 2003.

WONS, L.; SOUZA, R. de O. C. de; SILVA, H. de F. N.; FERNANDES, F. R. Barreiras ao compartilhamento do conhecimento nas organizações. Perspectivas em Gestão \& Conhecimento, João Pessoa, v. 8, número especial, p. 86-101, out. 2018.

ZACK, M. H. Managing codified knowledge. Sloan Management Review, v. 40, n. 4, p. 45-58, 1999. 